\title{
UNIVERSITY-ORGANISED SUMMER SCHOOLS AS CASES OF HYBRID EDUCATION
}

\author{
AGNĖ PODERYTE் \\ International Cooperation Department, Vytautas Magnus University \\ V. Putvinskio g. 23, Kaunas, Lithuania \\ E-mail address: agne.poderyte@vdu.lt \\ ORCID number: https://orcid.org/0000-0002-3864-2792
}

\begin{abstract}
Aim. The aim of the article is to discuss how summer schools can be approached as instances of hybrid education and how this can help to address the complex needs of their participants living in a culturally and technologically intertwined world.

Methodology. This paper analyses the theoretical framework of hybrid education, its manifestations in summer schools and - since it needs contextualisation - how it works in the specific case of the Baltic Summer University organised by Vytautas Magnus University (Kaunas, Lithuania).

Research and conclusion. To attract their target audience, summer schools combine academic content, and the elements of business and entertainment. This results in a separate mode of education with new possibilities and scope; however, it also poses a paradox: while the adoption of business and entertainment practices puts summer schools somewhat outside the realm of the traditional university practices, it makes higher education more approachable and able to react to the fast-changing reality. The Baltic Summer University fits the established pattern and as such, it could benefit from a more active engagement of this theoretical approach and the opportunities that it offers.

Originality. While summer schools are a relatively established phenomenon, they have recently witnessed a great expansion in both the supply of programmes and the interest from students. The nature of these programmes and the sudden interest in them remain under the radar of more extensive in-depth studies, which would actually help to harness their full potential.

Key words: summer school, short-term studies abroad, hybrid education, hybrid pedagogy, Baltic Summer University
\end{abstract}

\section{INTRODUCTION}

Cientific and technological developments result in boundless ways to be and Sbelong (Perdersen et al., 2018). The unprecedented configurations of realities require new sets of competences for the digital citizens of this brave new digital world to co-exist and make the best of the opportunities it offers. Education 
should help to address these new challenges, but in order to do so, it has to find ways to reflect and appeal to the complex identities of the residents of today's world. According to Irvin Varkonyi (2012), gone are the days when the university primarily dealt with "18 to 22 year olds, fresh out of high school" (p. 22). Instead, it is "now a complex organisation catering to undergraduate and graduate students of all ages: full-time and part-time students, enrolled students taking classes for credit and non-matriculating students who audit classes, degree seeking and certificate-focused students" (ibid.). The diversification of students also means that there are different motives for students to enrol on the course, study and seek education. This can be said to signify the shifting perception of the university and its function: the ever-changing reality demands constant update of one's skills, improvement of competences and conditions for continuous development. With the undeniable need to encounter and embrace the plurality of cultures and their configurations, various mobility options are available for students not only to gain education, but also to benefit from it taking place in a (multi)cultural context.

This is the place where university-organised summer schools come into play. They meet the need for continuous education and the development of skills without asking for a long-term commitment from the students (Lakkala et al., 2018). Moreover, with so many real-life and online options available, to address the needs of students with complex identities, such summer schools must offer something more elaborate in its nature than a mere course on subject $X$, with its value translated in price for credits.

As a result, summer schools cross the boundaries of the "bricks-and-mortar" (Varkonyi, 2012, p. 22) classroom and operate in physical, digital locations as well as in some third spaces emerging from interactions in multicultural settings. Therefore, the purpose of this article is to analyse how summer schools - as entities combining different approaches - can cater to students and their complex realities. The case study of the Baltic Summer University illustrates how this model works in practice.

\section{HYBRIDITY}

Hybridity primarily stems from what has been marginalised, cast into the shadows and deemed irrelevant as some by-product of clashing cultures and their powers. Yet this approach has proven very insightful and valuable, addressing the newly emerging realities and complications arising from this process.

According to Jane Kenway and Lindsay Fitzclarence (1999), in very general terms, what has given the way to hybridity and this disintegrated state of being is "the post-traditional order" (p. 301). According to them, there are various reasons for this shift, such as "the declining influence of traditional agencies of socialisation (for example, the church, the family and the school) and the rise of other major influences (for example, the media, and popular culture)" 
(ibid.). Re-echoed in most narratives is the idea that what makes things easier, also poses unprecedented challenges: "new scientific and technical developments, and social movements and their challenges to convention and habit, the clash of values brought about by the rise of global differences and the spread of different cultures around the globe" (ibid.). This parallel process of mixing and spread of cultures and the direction of this process taking place in both the virtual and the real world, has resulted in fragmented identities and states of being, difficult to label and sort into clear categories.

An important voice in the dealings with culture as the result of the postmodern and postocolonial realities is that of Homi Bhabha (1994), who claims that "histories and cultures constantly intrude on the present, demanding that we transform our understanding of cross-cultural relations" (Parsons et al., 2011, p. 4). As such, hybridity arose from the demand to focus on the "multicultural awareness as well as an effort to remove the negative connotations from terms such as hybrid, bastard or mongrel and infuse it with more positive potential and valuable productivity" (Pedersen et al., 2018, p. 228). Bhabha's work emphasises how valuable it is to see the world from the points, where different cultures meet, and find ways to interact, albeit in very diverse and uneven patterns. What this approach also brings to the table is the claim that the stories told by those "who have suffered the sentence of history - subjugation, domination, diaspora, displacement - that we learn our most enduring lessons for living and thinking" (Bhabha 1994, p. 171). The dialogue between those subdued and those who tell grand narratives, clumps culture into "uneven, incomplete production of meaning and value, often composed of incommensurable demands and practices, produced in the act of social survival" (ibid.). While still disproportionate because of power claims and strength of voices speaking in this conversation, this disfigured formation is still far more inclusive than the previously dominant grand narratives leaving place only for one reality and one truth.

The formation of cultural identities is further affected by digital technologies and their "ubiquitous and pervasive character" (Pedersen et al., 2018, p. 225), which "mediate communication, participation and forging of cultural identities" (ibid.). This can be traced back to Donna Haraway, who developed the theory of cyborg feminism, and who claims in her Cyborg Manifesto that "we are all chimeras, theorised and fabricated hybrids of machine and organism" (Haraway, 1991, p. 150). According to her, such hybridity of nature stems has been determined by the "developments in information technology, medical procedures, genetic engineering and other areas of technoscientific endeavour have made the world a more mixed up place" (Angus et al., 2001, p. 198). Therefore, bodies, technologies and cultures are all intertwined in the new modes of being.

Bhabha's (1994) claim about "an uneven, incomplete production of meaning" (p.172), is re-echoed in Haraway's work about the situated knowledge (1988), in whichsheclaimsthat" knowingself(which)ispartialinallitsguises,neverfinished, whole, simply there and original; it is always constructed and stitched together 
imperfectly, and therefore able to joining with another, to see together without claiming to be another" (p. 119). Both of these theories, while having different accents, actually speak about similar issues: everything is connected in this world in temporary, fleeting configurations of meanings, bodies, cultures and technologies. The next chapter will suggest how education can help to bring more clarity to this chaos by asking certain questions.

\section{HYBRID EDUCATION}

Education is another area where hybridity can be witnessed in a variety of forms, shaped by its purpose, or as Perdersen et al. have put it, by its why-ness (Perdersen et al., 2018, p. 232). The modes of hybridity can be rather straight-forward like the blend of online and class education that helps students to live and work in both of these modes and in between them, or it can, for example, combine classroom activities with community-based learning, "a broad framework that includes service-learning, experiential learning, School-to-Work, youth apprenticeship, lifelong learning and other types" (Owens \& Wang, 1996, p. 3), thus expanding the scope of learning outcomes to the wanted extent.

Various stakeholders bring their own expectations and preferred practices to the table, as in the case of academia-business cooperation (Kleinman et al. 2018), or when education and entertainment are looking for the middle ground and ways to coordinate their agendas and attract young people through the synthesis of both (Kenway and Fitzclarence, 1999). The opportunities are endless, and as Stommel and Rorabaugh put it so eloquently, "as we allow two things to rub up against each other, two things that might not otherwise touch, we incite them to interact, allowing synthesis (and even perforation) along their boundaries" (Stommel and Rorabaugh, 2012). In all the cases, new formations are greater than the sum of their separate parts and provide opportunities that these different actors could not achieve separately.

Hybrid education is valid because it allows "opening up new spaces, forms and understandings through the productive use of hybridity. Importantly, it is not a sequential blend of something like flipped classroom or blended learning that understands itself in sequences of online and offline, rather, it is something other, a new breed or something that is at least two places at once" (Pedersen et al., 2018, p. 228). Stommel and Rorabaugh echo this opinion claiming that educators "must open to random acts of pedagogy - to connections that are, like the web, associative and lively but sometimes violent and deformed. In this, hybridity is not always safe, moving incessantly (and dangerously) toward something new - something as yet undetermined" (Stommel and Rorabaugh, 2012). Therefore, when it comes to hybrid education, at its core there is openness, opportunities and being able to see connections between seemingly unrelated different aspects of reality. They actually must be fleeting and able to change together with the reality which they are bound to accommodate. 
In general, what hybridity and in its turn hybrid education shows us is that there is such an astounding diversity of factors coming into play, to such a varying capacity, and for a multitude of reasons, that it seems better justified to analyse specific cases rather than to try to encompass all opportunities - and at the same time, none of them. Pedersen et al. claim that to create a space "for educational innovation and transformation" (Pedersen, 2018, p. 232), it takes to put "the why-ness of design - the values and visions - before the how-ness and the what-ness" (ibid.). For example, if universities want to attract more external revenue, they might develop collaboration with businesses and offer business solutions or look for new services to offer for external recipients, the social characteristics of which will determine their approach. Therefore, without a more specific case, everything remains on a very theoretical level without actually showing how it can be employed. With this in mind, the next sections will discuss more specific cases of summer schools organised by universities and will explain what hybrid modes the summer schools employ and for what reason.

\section{SUMMER SCHOOLS AS CASES OF HYBRID EDUCATION}

While summer schools have become increasingly more popular, they have not been widely investigated yet, neither in terms of form nor content (Lakkala et al, 2018). They are seen as the peak in the trend of short courses abroad (Torenbeek \& van Rest, 2014), but also as a practice that can be extrapolated to commodify higher education. To make the schools more appealing, it is usually fused with certain entertaining aspects and this amalgamation of three different fields (education, entertainment and business) gives birth to a unique product that outwardly seems as a small-scale replica of long-term studies, but due to the intensity of studies, duration and additional factors that come into play, it can be treated as a new hybrid entity in its own right.

The reasons why summer courses have been organised by the universities and what function have they fulfilled has varied across time and different locations, but the model that has taken hold in the second half of the $20^{\text {th }}$ century and that is now employed by many universities can be actually related to the shift in the function of the university - mentioned previously in this article and pointed out by Varkonyi (2002) - that "universities are catering for an increasingly growing market of learners with increasingly complex needs" (p. 22). In this section, it will be argued that to meet this demand, summer schools as a service provided by the university combines the elements of business and entertainment. This combination of new elements allows attracting a new audience, but the "impurity" of this new creation might be approached with great distrust from the academic stakeholders because as Kenway and Fitzclarence (1999) claim, education is usually divorced from entertainment, even though such prejudice might cost academia some valuable channels to reach potential students. 
Before analysing how these three aspects operate in tandem, it is worth discussing the historical development of summer schools, as it reflects the gradual transformation of summer courses into something in their own right. According to Joroen Torenbeek and Edwin van Rest (2014), summer studies in universities can be traced back to as early as the $19^{\text {th }}$ century and the appearance of the third, summer semester in American universities as a means for students to speed up the study process and graduate as early as possible ( $\mathrm{p}$. 4). In the $20^{\text {th }}$ century, it appeared in the United Kingdom as well, yet with the purpose to open the university to the public and to enlighten the society, rather than to help students advance their studies (ibid.). Finally, at the end of the $20^{\text {th }}$ century, the now-usual summer course model took hold in Europe and raise to prominence parallel to student exchange programmes (ibid.). This model allows organisers to use the existing infrastructure that would otherwise remain unused during the summer months to earn additional revenue, improving university reputation by showcasing areas of study and research excellence and potentially attracting new exchange or full-time students.

From the formal point of view, this model consists of short courses offered during the summer months, provided by an accredited institution of higher education for people from all cycles of studies calculated to cover running costs and earn student ECTS credits (with some exceptions) (Torenbeek \& van Rest, 2014, p. 5). While certain variations are available, this is a concise model adopted by universities that offer summer programmes for students and other interested persons.

A very straightforward interpretation would point to a business-like transaction: students want extra credits, and universities want additional income. However, there are more actions that come into play and before they are introduced, it is worth discussing the mercenary aspect as well. In the context of the university, the development of summer schools, while increasingly prevalent, is treated as something disengaged from its official agenda, a "cash cow" (Torenbeek \& van Rest, 2014, p. 5) that puts university into the market as a service provider, and a student as a client in a more obvious equation, and this aim to earn revenue is sometimes perceived as bringing the university beneath its noble mission.

In the US, where universities frequently suffer from funding cuts, "the mingling of business and academic practices takes different forms and provokes different responses" (Kleinman et al., 2018, p. 561). There are various ways for business and academia to interact, sometimes looking for mutually beneficial partnerships and sometimes by the academic word overtaking marketing strategies. It is also worth mentioning that "hybrids vary from case to case because they emerge in distinctive local contexts" (ibid.), and what the analysis of each case of such hybrid interaction can bring, is understanding that cooperation in a variety of different forms and hybrid formations are possible. Kleinman et al. (2018), however, add to their warning that "organisational experiments at the business-academia interface are polysemous, may be subject to contradictory interpretations, and require theoretical caution" (p. 562). Therefore, there is a 
variety of forms that can take place and the focus at this stage falls on opportunities rather than established models.

In cases of summer schools, the ties with business practices are difficult to miss. Its content is adapted to meet the needs of the target audience (it might range from undergrads to students of specific fields as well as everyone who wants to learn something new during the summer holiday), marketed on various portals, such as Short Courses Portal ${ }^{1}$ or Summer Schools in Europe ${ }^{2}$. They have their separate websites ${ }^{3}$ from those of the institution, develop marketing campaigns and online presence through their Facebook ${ }^{4}$ pages and Instagram $^{5}$ accounts, develop pricing strategies (e.g. Early Bird), etc. In order words, they offer a product and market it as such.

While the mercenary aspect of summer schools is obvious, this commodification of something the university offers shows how it can actually serve as a tool for a university to react faster to what is happening in the world and to what the audience finds most relevant. Therefore, Torenbeek and van Rest (2014) claim that while summer schools may represent the well-established trend of short-time studies abroad, they may also be seen as signifying the emergence of something new, the trend of "higher education as a takeaway commodity, an interesting part of the development of more customised education in order to provide a quick solution to the need for individual profiling" (p. 3). Summer schools are fast to assemble: the cultural and social part remains the same, while the thematic course and academic content offered might change every year depending on what works and what does not. It is worth remembering, however, that while the university is granting credits, there is a high-quality level of studies to uphold and chasing trends should not be chosen over the possibilities to ensure high-quality content, as according to Lakkala et al. (2018), the pedagogic quality of courses remains as the most important criteria for potential students in most cases.

An important aspect to mention here is that since summer courses follow their potential students to the channels they frequent, strive to speak their language and appeal to topics they find relatable, they have developed quite prominent online visibility and are prone to employ tools of communication beyond the more conventional ones to get more immediate access to the students before, during and after the courses on various platforms (e.g. Instagram, Facebook, WhatsApp, Slack) and other tools that provide students a possibility to immediately reflect their summer experience on their social media by sharing photos and posts and interacting with new friends and teachers.

In short, what this employment of advertising practices has brought to the table is the willingness to open up to the world and address the fact that "digital practices of the students need to be incorporated into education or at least

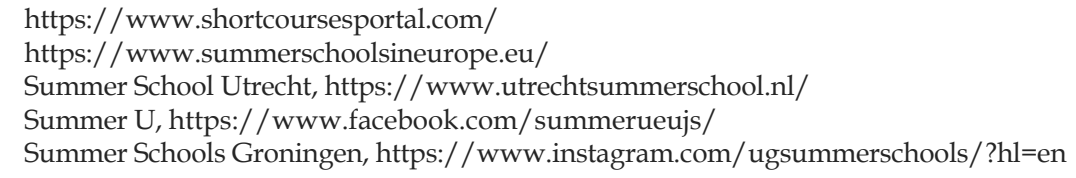


education needs to be reconfigured to be open to these cultural encounters" (Pedersen et al., 2018, p. 228). Therefore, trying to access students as potential clients through acknowledging their digital-selves can and should contribute to a more systematic approach to address their complex multicultural and multidimensional identities, assigning certain tasks in digital platforms and tailoring them in a way that helps the students to perform their identities in all mediums.

However, while universities might offer courses in their fields of excellence or something very site-specific, all descriptions of courses mention and even emphasise the dimension of entertainment, social and cultural programmes to be provided. Programmes offered usually feature three aspects: (1) academic content, (2) social/cultural programme, (3) the aspect of interculturality.

In fact, the second and the third parts of the programme might come into play as equally important as the first, "official" one: the change in environment and exposure to other cultures might be a factor as enticing as studying the subject offered and receiving credits for it. For example, Utrecht Summer School claims that alongside to courses, it "aims to provide its participants with an unforgettable stay in Utrecht and the Netherlands. In addition to the study programme, there is [...] the presence of an extensive social programme. Including city trips through the Netherlands (for example, to Delft \& The Hague), night canoeing through the canals of downtown Utrecht." ${ }^{6}$ Therefore, the entertainment part is an important aspect of short-term mobility as well, and is marketed together with the academic content offered.

However, as Kenway and Fitzclarence (1999) put it, "education is equated with high culture and print; consumer/media culture with low culture and the image; and preferably never the twain shall meet" (p. 309). This points to the problem of reluctance to mix the two as the second is presumably "tainting" the first. Yet the authors also add that "this view results in several paradoxes, in a time when entertainment, education and advertising become hybridised, and as children's education and schooling become commodified" (ibid.). While Kenway and Fitzclarence have addressed school education, the same sentiment is felt in higher education too. What summer schools are able to achieve through marketing and pursuit of more appealing formats is the disengagement from learning in classroom settings and embracing the fact that "education is taking place in a number of sites not limited to schooling" (Kincheloe and Steinberg, 197, p. 4). With this in mind, the entire time during the summer school can be seen as a territory where learning can take place. Even if a student comes to study Molecular Biology or Astrophysics, working in a different cultural setting and interactions with students from the same or different courses and from different countries might serve as an educating experience, especially if facilitated. Therefore, some non-intrusive additional tasks (e.g. scavenger hunting), while seen more as a game, can actually serve as an ice-breaker and a tool for new students to bond and get to know each other without putting the actual intention of such activities into the spotlight.

6 https://www.utrechtsummerschool.nl/about 
While the academic content provides a structure for courses and is the element that formalises and determines its nature (subject, duration, credits, etc.), and additional activities make it entertaining, appealing and educational in their own right, it is also important to mention that the courses take place in what has been earlier in the text hinted to be the third space. Originally coined by Bhabha (1994), third space marks the territory that emerges at the intersection of various cultures. Garšvė and Mažeikienè (2019) describe it as created by "participants with different transcultural hybrid identities (student-migrants) [...] through their interaction, where the fusion of different cultural horizons takes place and new cultural experience is gained by all participants (both students and teachers), all participants "enter a new cultural territory" and cross limits of own heterogeneous culture" (p. 1). Therefore, a summer school is exactly a place where irrespective of the geographical locality, an additional space opens up for everyone involved to act out their identities. With students coming from different locations, backgrounds and driven by different motivation, each time a course offers different configurations and conditions to experience cultural encounters. In the contexts where third spaces are bound to appear, caution must be practiced, because encounters with the unfamiliar might presuppose possible confrontation, tension, unpreparedness of a person and reluctance to encounter a person of a different culture (Kairè, 2018, p. 8).

Therefore, while students of summer courses are aware of the fact that they will meet people of other cultures, with students applying from all over the world, summer school organisers should think of non-intrusive ways for future participants to exercise their cultural identities, reflect on their personal experiences and acknowledge them during the courses or avoid the spotlight if they want to. Certainly there are usually activities that celebrate different cultures in various get-togethers developed for the purpose of introducing different cultures through cuisines, games and music, there is a considerable section of students who do not have a clear-cut homogenous identities and such activities while entertaining, do not create the outlet for them to exercise their own identities.

\section{CASE STUDY OF BALTIC SUMMER UNIVERSITY}

Baltic Summer University (BSU) premiered in 2017 and adopted the course model of its predecessor, Lithuanian Language and Culture Summer Course offered at Vytautas Magnus University since 1999. All courses added under the umbrella term of "summer university" feature the same elements: (1) lectures / activities related to the academic subject; (2) lectures / activities related to the culture of the host country; (3) social programme addressing the diversity of students participating in courses / intercultural dimension of courses.

Just like the theoretical model discussed above, Baltic Summer University employs marketing strategies and has developed a social media presence. First of all, it has its own brand identity and to put emphasis on its scope, it is calling 
itself a summer university rather than a summer school. It has its own logo (always depicted side-by-side with that of Vytautas Magnus University), and its descriptor Baltic rather than Lithuanian shows its orientation towards the market which sees Lithuanian as any other country of the Baltics, presumably the markets outside Europe.

Every year, it develops a different slogan or the campaign; this year, inviting the candidates to their superpowers ${ }^{7}$. Both the visual representation (reminding the sign of the Superman) and the slogan itself are the reference to the popular culture, implying that the organisers are more facilitators of education helping students who want to awaken their inner potential themselves. The same message is communicated and coordinated across all platforms where BSU is present: Instagram ${ }^{8}$, Facebook ${ }^{9}$, the official website of BSU $^{10}$ and its page on the institutional website ${ }^{11}$.

Student motivation can also be diversified on a variety of bases, evident even from how their studies are funded: recent years have witnessed an increase in the cases of self-funded studies (Torenbeek \& van Rest 2014). Students who pay for their studies, according to their motivation letters (data from 2019 and 2020), can be driven by a variety of reasons, ranging from direct benefit for their degree studies, desire to travel abroad and study in a different country for a short period of time, etc. The short period of studies is also an advantage for partner universities which might fund a group of students to come for summer courses and rely on their feedback for further cooperation strategy and, consequently, students coming for a semester or a full year of study. Some students can receive funding to join this course. There are scholarships available from Education Exchanges Support Foundation (EESF) to study at Lithuanian Language and Culture Summer Courses for foreigners and foreigners of Lithuanian origin which both covers the tuition fee and issues a scholarship for students to arrive at Lithuania.

The motivation of students can also be determined by the nature of the courses themselves. The most open-ended and diverse programme in terms of participant composition and motivation is Lithuanian Language and Culture Summer Course. The nature and structure of this course, as mentioned above, lends itself easily to a variety of students with different profiles and backgrounds. The analysis of student applications reveals that the motivation to join this course serves as a gateway to the country, the city and the university it hosts. Students are divided on the basis of their language level from the beginners to advanced students; thus, both new and returning students are welcome, it is the course that predominantly attracts students of Lithuanian origin, from students with Lithuanian roots to Lithuanian parents who raise their children abroad and want them to spend some time in Lithuania and

7 The cover photo of Baltic Summer University's Facebook page, https:/ / www.facebook.com/ BalticSummerUniversity/photos/p.2197956856974262/2197956856974262/?type=1\&theater 8 https://www.instagram.com/balticsummeruni/

9 https://www.facebook.com/BalticSummerUniversity

10 http://balticsummeruniversity.com/

11 https://www.vdu.lt/en/studies/baltic-summer-university/ 
learn Lithuanian language. It welcomes linguists who study languages, students from the centres of Baltic studies abroad, students who might consider exchange programmes of a longer duration here in Lithuania, foreigners who already study in Lithuania, people interested in learning other languages, retired people who want to learn new things and those who simply want to spend a portion of their summer in a culturally diverse environment. This impressive variety of motivations to study the Lithuanian language and culture re-echoes Varkonyi's claim that universities have expanded the scope of students they cater to (Varkonyi, 2012, p. 22). Moreover, the fact that this course is the most culturally engaged and the most popular at the same time, might be related to Bhabha's claim about the increasing attention to those who have been previously marginalised and even removed from the grand narratives and are now getting back to the spotlight as their stories of resilience and survival are deemed to be worth to be acknowledged and learned from.

Every year, Baltic Summer Course attracts over one hundred students from almost 30 countries. As a result, education in such case takes place not only in Kaunas, Lithuania, but in Bhabha's terms, in "the third place" as well. Moreover, every year, a new set of participants from different countries make sure that cultural encounters are never the same even for a person who comes back several years in a row. While in general cultural encounters end up being pleasant occasions bringing the added value to the entire experience, certain pitfalls must be also taken into consideration. Critical days are the first ones: fatigue after the long trip, unfamiliar place, foreign language, homesickness and new people from different backgrounds is indeed a stress-inducing combination, and students should be informed that such issues might occur and that it is perfectly normal to feel overwhelmed.

Some activities are specifically designed to target the danger of cultural domination and introduce a variety of perspectives: the opening lectures for the entire Baltic Summer University are delivered by a foreigner and deal with his or her subjective experience of Lithuania, even what mishaps take place due to cultural differences, and small narratives in all of their manifestations are more than welcome. Students are invited to the international party, where they are not only introduced to the local cuisine and some traditional music and games but are encouraged to showcase these aspects of their own countries which they mostly welcome with great enthusiasm. For several years, the closing ceremony features a performance by the summer choir: students are invited to join a summer choir, in which they rehearse and prepare a performance that features both Lithuanian songs and songs of their language. Students are also welcomed to perform in any other way they choose and present their personal talents or introduce their culture, ranging from poetry reading to dancing, yoga demonstrations and playing tanpura. As already mentioned, the courses might be an opportunity to improve one's knowledge in a specific field. Such courses usually target a narrower group of students (e.g. Methods in Molecular Genetics, Investigation to Biodiversity) but because of their constant involvement in social and cultural activi- 
ties and interaction with students from other courses, they develop cross-cultural competences as well.

Therefore, the case of BSU reflects the theoretical model of a summer school established in the article. Its three-fold composition includes academic courses as the most official, institutional part, that defines the formal structure of the courses (the subject, duration, credits, price, etc.), social and cultural activities added for entertainment and the intercultural experience that emerges naturally from the interaction of people from different background and cultures. While BSU is a part of the institutional narrative, it has developed a distinctive identity resulting from its incorporation of business (marketing) and entertainment elements.

\section{CONCLUSION}

Hybrid education practices serve not as a strict set of rules of how to combine different elements of education and other areas. Instead, hybrid education invites taking the complexity of identity, cultural and technological amalgamations into consideration, and finding ways to address them through education. The increasing popularity of summer schools can be explained by their ability to cater to the fast-changing needs of students emerging from the fast-changing reality and their desire to travel and experience third spaces. Thanks to their brevity and cyclical nature, summer courses can address the constant need to learn, travel and test oneself in different contexts without a long-term commitment. While summer schools remain a part of the university's narrative, they develop distinctive identities through their adoption of entertainment and business practices (and potentially other operating factors), which makes the content of higher education more approachable yet, as some add with disapproval, commodified.

\section{REFERENCES}

[1] Angus, T., Cook, I., \& Evans J. (2001). A Manifesto for Cyborg Pedagogy? International Research in Geographical and Environmental Education, 10(2), 195-201.

[2] Bhabha, H.K. (1994). The location of culture. London: Routledge.

[3] Garšvė, L., \& Mažeikienė, N. (2019). Being In-Between and Nowhere: A Hermeneutic Approach to Negotiating Transcultural and Third Space Identities. In: G. von Carlsburg Ed.), Transkulturelle Perspektiven in der Bildung [Transcultural Perspectives in Education]. Berlin: Peter Lang GmbH, 1-15.

[4] Haraway, D. J. (1991). Simians, Cyborgs and Women: The Reinvention of Nature. NewYork: Routledge.

[5] Haraway, D. J. (1988). Situated knowledges: The science question in feminism and the privilege of partial perspective. In: J. Agnew, D. Livingstone \& A. Rogers (Eds.) Human Geography, an Essential Anthology (pp. 108-28). Oxford: Blackwell.

[6] Kairè, S. (2018). Mes vienoje valtyje, bet aš vis tiek iš kitos kultūros: išgyvenimai mokantis daugiakulturrese grupese mobilumo metu [We are one the same boat, yet I am from another culture: the lived experiences of learning in group during mobility]. Vilnius: Vilniaus universitetas. 
[7] Kenway, J. \& Fitzclarence, L. (1999). Designing generations: Hybridising entertainment, advertising and education. Entertainment, advertising and education. Australian Journal of Education, 43(3), 300-316.

[8] Kincheloe, J. \& Steinberg, S. (Eds.). (1997). Kinder-culture: The corporate construction of childhood. Boulder, CO: Westview Press.

[9] Kleinman, D. L., Feinstein W., Downey, G. D., Peterson, S. \& Fukada, Ch. (2018). Hybrid Experiments in Higher Education: General Trends and Local Factors at the Academic-Business Boundary. Science, Technology, \& Human Values, 43(3), 540-569.

[10] Lakkala, M., Ilomäki, L., Mikkonen, P., Muukkonen, H., \& Toom, A. (2018). Evaluating the pedagogical quality of international summer courses in a university program. International Journal of Research Studies in Education, 7(2). 89-104.

[11] Owens, T. R. \& Wang. Ch. (1996). Community-Based Learning: A Foundation for Meaningful Educational Reform. Service Learning 37(1), p. 1-24. http://digitalcommons.unomaha.edu/ slceslgen $/ 37$

[12] Parsons J. B., Kelly J. \& Harding K. J. (2011). Post-Colonial Theory and Action Research. Turkish Online Journal of Qualitative Inquiry, 2(2), 1-6.

[13] Pedersen, A. Y., Nørgaard, R. T., \& Köppe, C. (2018). Patterns of Inclusion: Fostering Digital Citizenship through Hybrid Education. Educational Technology \& Society, 21(1), 225-236.

[14] Stommel, J. (2012). Hybridity, pt. 2: What is hybrid pedagogy? Retrieved from http://www. digitalpedagogylab.com/hybridped/hybridity-pt-2-what-is-hybrid-pedagogy/

[15] Stommel, J., \& Rorabaugh, P. (2012). Hybridity, pt. 3: What does hybrid pedagogy do? Retrieved from http://www.digitalpedagogylab.com/hybridped/hybridity-pt-3-what -does-hybrid-pedagogy-do/

[16] Varkonyi, I. (2012). Hybrid Education: Combining the Benefits of Face-to-Face Learning with Online Distance Learning! Defence Transportation Journal, 68(1), 22-23, 28. 